\title{
Antena Dipolo Planar
}

\author{
Christian Pinheiro, Édson dos Santos Sousa, Jean Almeida Cordeiro e José Felipe Almeida
}

Resumo- Neste trabalho é proposto a confecção e medidas de uma antena dipolo planar. A antena é projetada para operar na faixa de 2,4 GHz. A finalidade da antena é servir de um aparelho de estudo didático, devido a maneira como foi construída. Para isto, a antena possui dois pinos laterais, os quais servem de ajuste ao espaçamento compreendido entre o plano da antena e seu plano de terra. Na faixa de $2,41 \mathrm{GHz}$ é verificada uma largura de banda de aproximadamente $30 \%$.

Palavras-Chave-Antena dipolo planar, largura de banda.

Abstract - In this work is considered the confection and measures of a planar dipole antenna. The antenna is projected to operate in $2,4 \mathrm{GHz}$. The purpose of the antenna is to serve of a device of didactic study. In order, are used two lateral bolts, which serve of adjustment to the displacement between the antenna and its ground plane. In the band of $2,41 \mathrm{GHz}$, a bandwidth of approximately $30 \%$ is verified.

Keywords - planar dipole antenna, bandwidth.

\section{INTRODUÇÃO}

Em antenas planas, o aumento da superfície efetiva é uma característica capaz de impor modificações a seu funcionamento [1-4]. Um exemplo disso é o aumento da largura de banda [2]. Antenas com essa característica são de pleno uso em ERBs (Estações Rádio Base). Com essa forma pode-se projetar antenas bastante conhecidas de tal maneira que ao invés do arame (ou tubos de alumínio) se use uma chapa de espessura desprezível. Como exemplos estão as antenas monopolo e a dipolo [5].

Neste trabalho é feita a confecção de uma antena dipolo planar. Esta antena tem as mesmas características da antena dipolo simples [5], entretanto, sua ênfase se evidência na largura de banda. A antena foi dimensionada para operar na faixa de 2,41 GHz. O modelo apresentado é composto de lâminas metálicas posicionadas paralelamente ao seu plano de terra. Os resultados experimentais são aqui apresentados em termos do parâmetro de perdas da antena.

C Pinheiro, E. Santos, J. A. Cordeiro e J. F. Almeida, Instituto de Estudos Superiores da Amazônia-IESAM, Belém do Pará, Brasil, E-mail: cpg.telecom@yahoo.com.br, felipe@lane.ufpa.br

\section{Modelo e Resultado Obtido}

No modelo da antena deste projeto foi utilizada uma placa de circuito impresso. Isto se torna necessário devido à sustentação das partes que irão compor toda a estrutura. Este tipo de material é de fácil aquisição e de custeio muito econômico. O dimensionamento da antena está mostrado na Fig. 1.

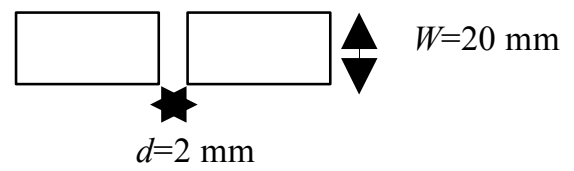

(a)

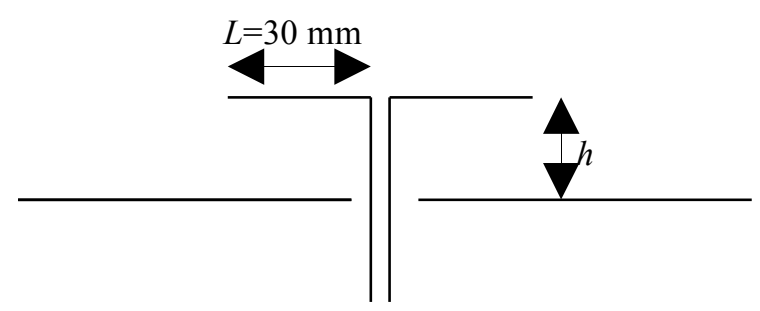

(b)

Fig. 1. Dimensionamento do modelo da antena proposta.

Na Fig. 1 é mostrado uma ilustração do modelo utilizado neste trabalho e seu dimensionamento. Cada braço do dipolo tem comprimento $L=30 \mathrm{~mm}$ e é constituído por uma lâmina (Fig.1(a)) de largura $W=20 \mathrm{~mm}$. O distanciamento entre cada dipolo foi fixado em $2 \mathrm{~mm}$. A altura $h$ do dipolo em relação ao plano-terra foi projetada de tal maneira que se possa fazer variar. Na Fig. 2 é mostrado o material utilizado para a preparação da antena.

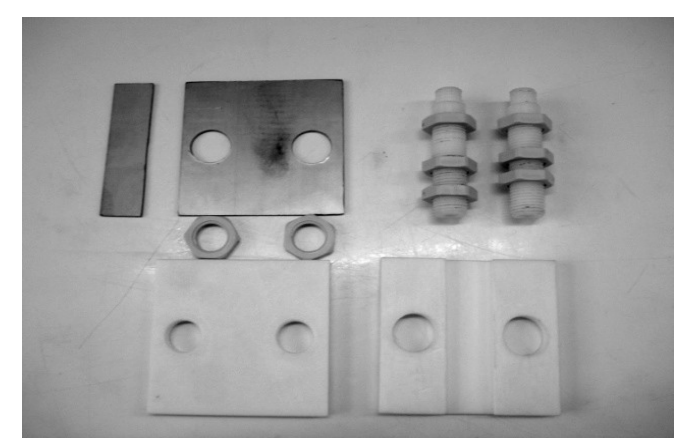

Fig. 2. Material utilizado. 


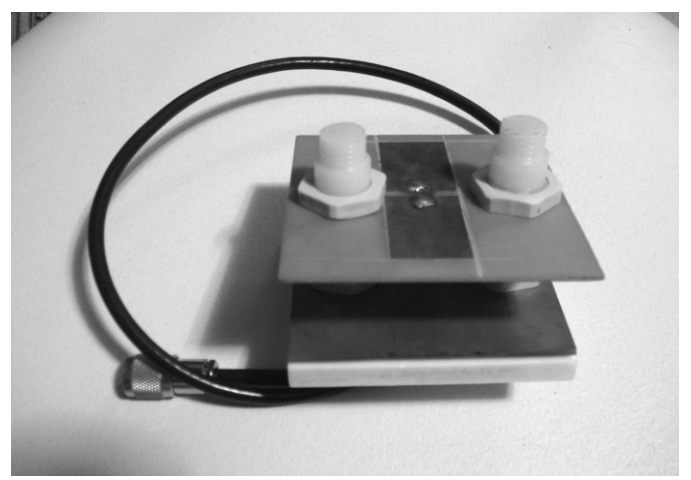

Fig. 3. Protótipo da antena.

A Fig. 3 mostra a antena proposta neste trabalho. Na linha de alimentação e em seu conector são usados materiais especificados por $50 \Omega$. A finalidade dos parafusos de ajustes é a de elevar (altura $h$, na Fig.1(b)), ou baixar, o plano da antena em relação ao plano de terra, para que durante as medidas se possa fazer o casamento de impedância da antena com a sua linha de alimentação para uma determinada freqüência específica. Note-se que um modelo como este apresenta uma modelagem bastante adequada para um estudo didático sobre os parâmetros de perdas e freqüência de operação em função de $h$. Além disso, os efeitos devidos à inclusão de materiais dielétricos abaixo do plano metálico da antena, também podem ser analisados, entretanto, no momento isto não é o objetivo.

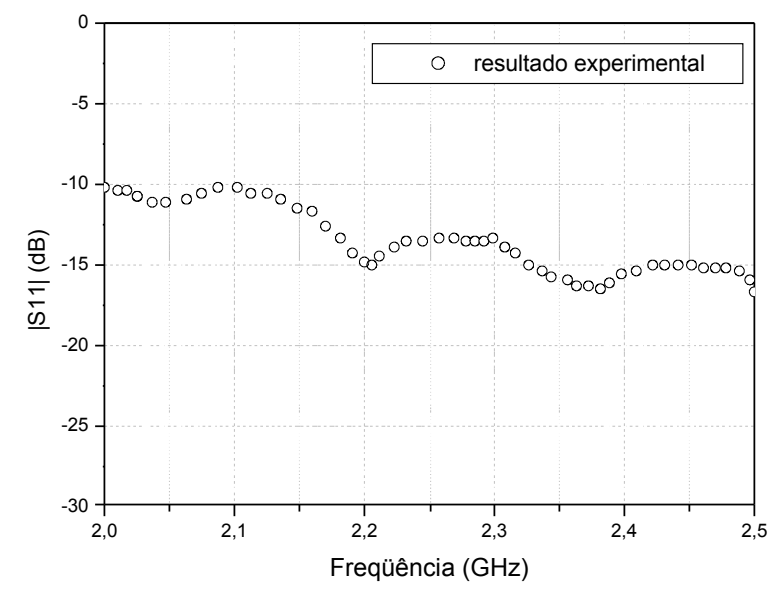

Fig. 4. Perdas de retorno (em dB) da antena no intervalo entre 2,0 e $2,5 \mathrm{GHz}$.

A Fig. 4 se refere às perdas de retorno da antena mostrada na Fig. 3. Com o ajuste da altura para $h=3,9 \mathrm{~cm}$, obteve-se o melhor VSWR - sendo medido 1,35 na freqüência central de $2,41 \mathrm{GHz}$. Note-se, nesta figura, que a antena passa a operar a partir de $2,1 \mathrm{GHz}(-10 \mathrm{~dB})$ indo até $2,5 \mathrm{GHz}(2,5 \mathrm{GHz}$ é a máxima freqüência em que se pode medir devido às limitações do aparelho utilizado (SiteMaster)).

\section{Conclusões}

Este trabalho apresentou a confecção e medida de uma antena dipolo planar. O modelo apresentado é composto de lâminas metálicas dispostas de forma paralela ao plano de terra da antena. Este tipo antena pode ser usado didaticamente para a observação da variação do casamento de impedância, para uma freqüência especificada, quando são feitas variações no espaçamento plano da antena/plano de terra - embora outros fatores também possam contribuir para isto, como é o caso do espaçamento entre as lâminas ou a largura da lâmina. O projeto levou em consideração a faixa de 2,41 GHz, devido o aspecto de uso prático. Os resultados, aqui mostrados, foram obtidos em termos do parâmetro de perdas da antena. Observou-se ainda, uma largura de banda de aproximadamente $30 \%$ (até $2,5 \mathrm{GHz}$, devido às limitações do analisador SiteMaster.

\section{REFERÊNCIAS}

[1] Y. Rikuta and R. Kohno, "Planar Monopole Antenna with Dual Frequency for UWB System", IEEE Antennas and Porpag. Magazine, 2003.

[2] T. Taniguchi and T. Kobayashi, "An Omni directional and Low-VSWR Antenna for Ultra-Wideband Wireless Systems", Radio and Wireless Cont. pp.145-148, Aug. 2002.

[3] N. P. Agrawall, G. Kumar and K. P. Ray, "Wide-Band Planar Monopole Antennas, IEEE Antennas Propagat., vol.46, no.2, pp.294-295, Feb. 1998.

[4] H. Schantz, The Art and Science of Ultrawideband Antennas, Boston, Artech Hause, 2005.

[5] A . C. Balanis, Antenna Theory: Analyzes and Design, New York: Adilson and Wesley, 2000. 